\title{
3D Finite Element Model Simulating the Behaviour of Filling Soils Used to Set Up a New Placement Method for Separate Sewer Systems
}

\author{
Alaa Abbas ${ }^{1}$, Felicite Ruddock ${ }^{1}$, Rafid Alkhaddar ${ }^{1}$, Glynn Rothwell ${ }^{2}$, Iacopo Carnacina ${ }^{1}$, \\ Robert Andoh ${ }^{3}$ \\ 1. Department of Civil Engineering, Liverpool John Moores University, Liverpool, L3 3AF, UK \\ Email: a.h.abbas@2015.ljmu.ac.uk,f.m.ruddock@ljmu.ac.uk,r.m.alkhaddar@ljmu.ac.uk, \\ i.carnacina@ljmu.ac.uk \\ 2. Department of Maritime and Mechanical Engineering, Liverpool John Moores University, Liverpool, L3 3AF, \\ UK \\ Email: g.rothwell@ljmu.ac.uk \\ 3. AWD Consult Inc., 32 Vista Drive, South Portland, ME 04106, USA \\ Email: bandoh@awdconsult.com
}

Received: 22 November 2018; Accepted: 16 December 2018; Available online: March 152019

\begin{abstract}
The use of a finite element (FE) method and selection of the appropriate model to simulate soil elastoplastic behaviour has confirmed the importance and sensitivity of the soil properties on the accuracy when compared with experimental data. The properties of the filling soil play a significant role in determining levels of deformation and displacement of both the soil and subterranean structures when using the FE model simulation. This paper investigates the impact of the traffic load on the filling soil deformation when using the traditional method, one pipe in a trench, and a new method, two pipes in a single trench one over the other, for setting up a separate sewer system. The interaction between the buried pipes and the filling soils has been simulated using an elastoplastic FE model. A modified Drucker-Prager cap constitutive model was used to simulate the stress-strain behaviours of the soil. A series of laboratory tests were conducted to identify the elastoplastic properties of the composite soil used to bury the pipes. The FE models were calibrated using a physical lab model for testing the buried pipes under applied load. This allows the FE model to be confidently upgraded to a full-scale model. The pipe-soil interactions were found to be significantly influenced by the soil properties, the method of placing the pipes in the trench and the diameters of the buried pipes. The deformation of the surface soil was decreased by approximately $10 \%$ when using the new method of setting up the separate sewer.
\end{abstract}

Keywords: Elastoplastic; Modified Drucker-Prager cap constitutive model and Soil-pipe interaction.

\section{Introduction}

Soil is a media in which many infrastructure objects are embedded, such as pipelines and a variety of underground structural materials. One of the more complicated challenges facing designers is considered to be predicting the behaviour of a system when its structure and materials interact with the soil. The complexity of soil texture, which includes different types of solid matter peppered with voids filled by air or water, generates a variety of soil stiffness and elastoplastic behaviour. Therefore, it is important to identify the properties of the soil to predict soil behaviour when designing underground structures [1]. The cost associated with the compaction process and selection of a filling material is considered one important criterion regarding the safety and economic design of any drainage system and selecting the filling soil material [2]. The separate sewer system (SSS) is more common today in the UK, EU and the USA for all new developments. It is proposed as one solution to avoid the negative impact of combined sewer systems. Installing the traditional separate sewer system in narrow streets, which are more common in residential areas in the UK and EU, is challenging. The high initial cost of the traditional separate sewer system and the large area required to host the two sets of pipelines are considered the main barriers to using this system. This research proposes a new method for installing a separate sewer system: using one trench to accommodate two PVC pipes, one over the other, storm pipe at the top and sanitary pipe at the bottom. A normal composite soil available within the UK territory and used to embed sewer systems was used to bury the pipe system. A validated finite element model has been used to simulate the behaviour of the new system, which required a series of laboratory tests to identify both soil and pipes' properties. Identifying the soil properties was essential to extract the elastoplastic parameters of the soil for accurate simulation. Many studies have used the finite element (FE) model to characterise a variety of factors that influence the infrastructure behaviour [3-11]. They reported 
that the FE method is reliable for estimating the structural performance of underground structures compared with empirical methods. There are more than just soil constitutive models embedded in the finite element commercial packages to simulate soil behaviour; for example, nonlinear Duncan and Selig soil models to simulate the soil behaviour have been used by Kang et al. [12] to study the proper soil cover depth that can protect underground structures, using a 2D FE model. The FE model used to simulate the performance of flexible pipes subjected to a backfill soil depth of 6.1 and $12 \mathrm{~m}$ for two years incorporated a series of triaxial compression tests conducted in the laboratory to identify soil properties. The study revealed that the FE results tended to underestimate the pipe deflections and to overestimate the soil strain [13]. McGrath and Moore [14] developed a design procedure using a two-dimensional FE model for buried flexible pipes. A laboratory test was compared with the FE model to evaluate the model's effectiveness at estimating pipe behaviour under deep burial. It was found that the performance of the FE approach is essential in selecting the appropriate constitutive model to characterise soil behaviour. The importance of conducting studies into the soil deformations in sewer-laying projects is due to the permanent deformation of road surfaces which results from the traffic load, which is considered one of the important factors in road surface design, and the drainage system integrity [15]. The rutting that occurs in filling soil used in buried pipe systems is one of the primary distresses in road systems. It is caused by the permanent deformation in the surface layer of the foundation soil. The FE technique is receiving increased attention for simulating pavement and soil behaviour under live loads because of its versatile implementation of material characteristics and ability to examine the performance of the underground system structure [16]. However, there are limited studies investigating the surface soil deformation when using two flexible pipes buried in one trench, one over the other. This research studies the rut print of the traffic load on the filling soil used to bury two pipes in a single trench, one over the other, compared with soil deformation of the traditional system when only one pipe is laid in the trench. Two cases were investigated, one where there is a pavement at the soil surface and the second without the pavement. The paper is structured to describe the procedure of identifying soil material properties for the FE model. The boundary conditions and interaction of the FE model were validated compared with the experimental results produced from the physical model. The validation process enabled the FE model to be confidently upgraded to a full-scale model.

\section{Soil properties}

Two types of soil have been used to bury the pipe, according to British standard requirements [17]: composite soil, which is used as a filling soil, and granular soil, which is used as a bedding layer. The bedding layer properties were prepared and identified by the manufacturer. The filling soil properties, mechanical characteristics and elastoplastic behaviour have been defined through a series of laboratory tests. The sieve analyses, standard protector test and jar test have been applied to filling soil specimens to identify the mechanical properties. The triaxial and consolidation tests have been used to determine the elastoplastic behaviour of the composite soil.

\subsection{Mechanical properties}

Sieve analyses (grain size distribution) were applied to identify the physical properties of the soils, using a set of standardised sieves. Sieves with opening sizes ranging from $0.075 \mathrm{~mm}$ for sieve no. 200 to $4.75 \mathrm{~mm}$ for sieve no. 4 were used to analyse the soil. The results from this test were used to classify the type of the soil based on the Unified Soil Classification System (USCS). Three samples were selected randomly from the raw soil to conduct the test; results of the sieve analyses presented in Figure 1. Figure 1 shows that the top soil was classified as SPSM (silty sands, sand-silt mixtures, more than $50 \%$ passes no. 4 sieve, more than $50 \%$ retained on no. 200 sieve) according to the USCS. The soil is of medium grade, based on values of uniform coefficient $C_{u}=6.6$ and curvature coefficient $C_{c}=0.5$, making it suitable for use as a filling soil [18].

A specific gravity $\left(G_{s}\right)$ is the unit weight of soil solids to the unit weight of water. A jar test was conducted to identify the specific gravity for the filling soil. To determine and achieve the required compaction for the filling soil, a 90\%-95\% compaction degree, the standard protector test (Figure 2) was applied to the filling soil specimen to determine the maximum dry unit weight $\left(\gamma_{d}\right.$-max) and the corresponding optimum moisture content $\left(\omega_{\text {opt }}\right)$. These were $1.828 \mathrm{~g} / \mathrm{cm} 3$ and $12.6 \%$, respectively.

\subsection{Elasticity and plasticity properties of the soil}

Soil is considered an elastic-plastic material within which strain increments are additively composed of part elastic and part plastic (equation 1). This is according to conventional plasticity theory, such as the CoulombMohr hypothesis and Drucker-Prager's criterion, which are used as a yield or fracture condition, predominantly for granular and geological materials [19].

$$
d_{\varepsilon}=d_{\varepsilon e}+d_{\varepsilon p}
$$

where $d_{\varepsilon}=$ total strain, $d \varepsilon e=$ elastic strain, $d \varepsilon p=$ plastic strain. 


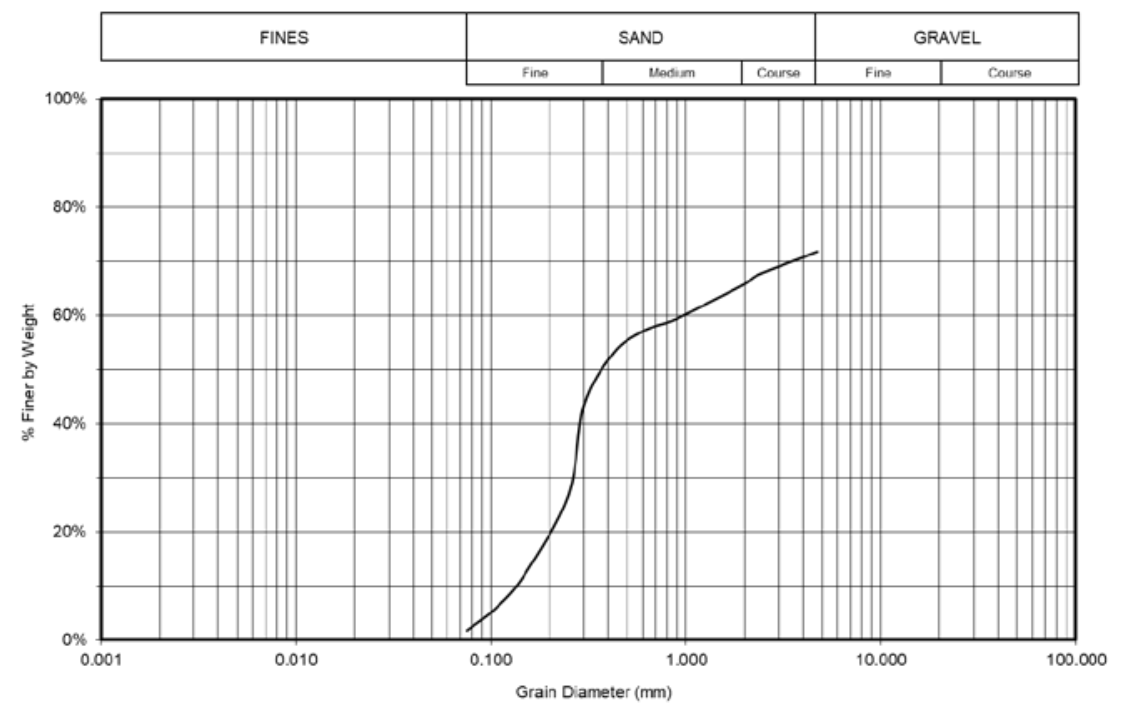

Figure 1. Particle size distribution curve of the composite soil.

Max. Proctor Density

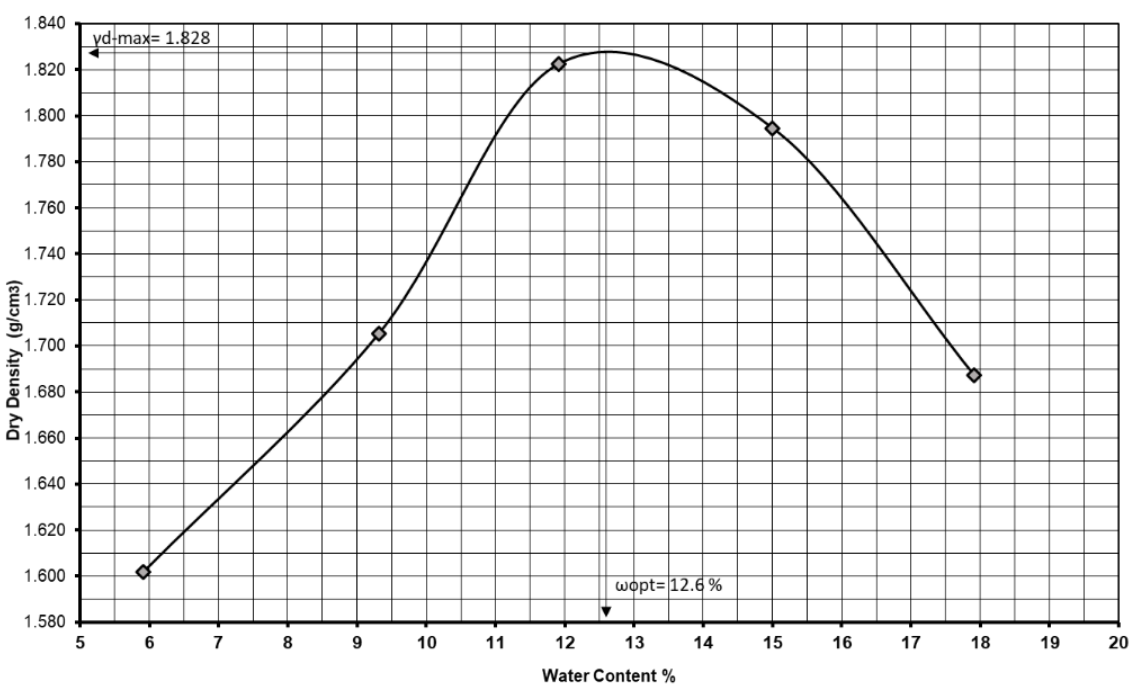

Figure 2. The curve of compaction.

There are many soil constitutive models which propose to simulate elastoplastic soil behaviour. However, designers often face difficulties selecting the most appropriate constitutive soil model for numerical modelling. The analysis type, kind of material and range of pressure/stress, in addition to an in-depth understanding of the concepts of constitutive methods, are the main factors which direct the choice of model. Limitations and advantages of each model in solving engineering case studies, the type of input data which is required and availability of data obtained from a range of laboratory tests are other factors of consequence when choosing a constitutive model [20]. The modified Drucker-Prager cap constitutive model has been used in this research; the model was required to identify specific parameters of soil such as soil modulus (E') and Poisson's ratio (v), to identify the elastic components of the stress-strain relationship and unload-reload curve, to identify the plasticity of the soil. Drucker-Prager (Equation 2) is used to model frictional materials which are typically granular, such as soils and rock, that exhibit pressure-dependent yields, and where the compressive yield strength is greater than the tensile yield strength (the material becomes stronger as the pressure increases). The Drucker-Prager plasticity model has been widely used in finite element analysis programs for a variety of geotechnical engineering applications.

$$
F_{s}=t-p \tan \beta-d
$$

where, $\beta$ is the friction angle measured at high confining pressure, $d$ its cohesion in the $p-t$ plane. 
$t=\frac{q}{2}\left[1+\frac{1}{K}-\left[1-\frac{1}{k}\right]\left[\frac{r}{q}\right]^{3}\right]$

$K$ is the ratio of the yield stress in triaxial tension to the yield stress in triaxial compression, thus controlling the dependence of the yield surface on the value of the intermediate principal stress. To ensure that the yield surface remains convex requires $0.778 \leq K \leq 1$. The Modified Drucker-Prager/Cap plasticity gathers the Drucker-Prager shear failure and compression cap yield surface which causes the material to compact (Figure 3). This model is appropriate for soil behaviour because it is capable of considering the effect of stress history, stress path, dilatancy and the effect of intermediate principal stress [21].

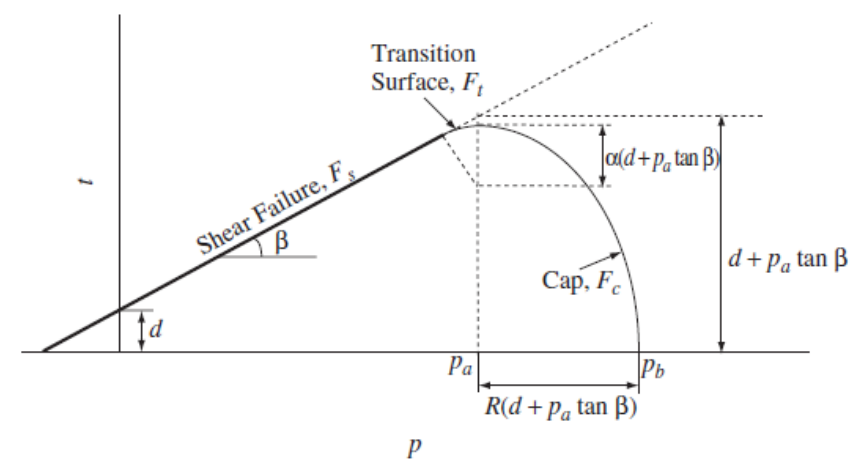

Figure 3. Yield surfaces of the modified Drucker-Prager cap model in the p-t plane (permission according to Copyright Dassault Systemes Simulia Corp) [21].

The cap yield surface is defined in Equation 4 as a function of volumetric plastic according to the consolidation mechanism.

$$
F_{c}=\sqrt{\left(p-p_{a}\right)^{2}+\left(\frac{R t}{1+\alpha-\alpha / \cos \beta}\right)^{2}}-R\left(d+p_{a} \tan \beta\right)=0
$$

where $R$ is a material parameter that controls the shape of the cap and $\alpha$ is a small number (typically, 0.01 to 0.05 ) used to define a smooth transition surface between the Drucker-Prager shear failure surface and the cap:

$F_{t}=\sqrt{\left(p-p_{a}\right)^{2}+\left[t-\left(1-\frac{\alpha}{\cos \beta}\right)\left(d+p_{a} \tan \beta\right)\right]^{2}}-\alpha\left(d+p_{a} \tan \beta\right)=0$

The hardening-softening behaviour is described by an evolution parameter $\left(p_{a}\right)$ which is a function of the volumetric plastic strain $\left(P_{b}=P_{b}\left(\varepsilon_{\text {plvol }}\right)\right)$ and the mean effective (yield) stress. A one-dimension consolidation test is used to obtain this function using unloading-reloading cycles. Equation 6 is used to calculate the evolution parameter $\left(p_{a}\right)$.

$$
P_{a}=\frac{P_{b}-R_{d}}{1+R \tan \beta}
$$

The modified Drucker-Prager cap constitutive model was selected for use in the simulation because of its accuracy and its ability to simulate the plastic behaviour of the soil relative to effective stress for the long term, such as when it is exposed to moving load. Triaxial and consolidation tests were carried out to identify the model parameters for the soil.

\subsubsection{Triaxial test}

The triaxial compression test is an effective method to determine the stress-strain behaviour of soil under different confining pressures, and is used by the FE package to identify the elastoplastic properties of the soil. A triaxial Consolidated-Undrained (CU) test was conducted on undisturbed soil specimens obtained from the physical models after the soil was compacted in the trench. The soil specimens were extracted from the trench from the first layer of the soil and from underneath the buried pipes. The test was conducted for each filling soil layer: below and above the buried pipes. In total, 12 tests were conducted; Figure 4 shows the results of the three triaxial tests under three confining pressures. 


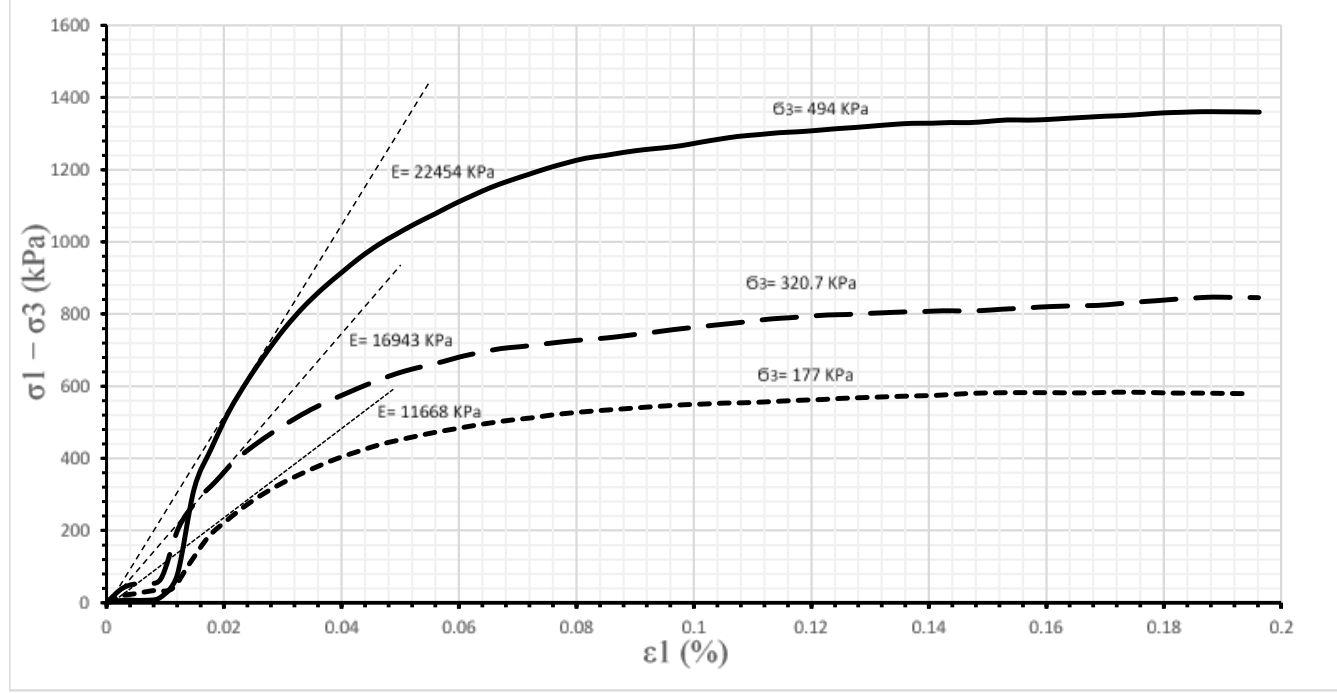

Figure 4. Results of the three triaxial tests under different confining pressures.

The triaxial test results were used to identify the soil friction angle and cohesion for the Drucker-Prager model. Figure 5 illustrates the soil friction angle $(\beta)$ and cohesion $(d)$ for the Drucker-Prager model from the effective stress $(p)$ plotted against the shear stress $(q)$.

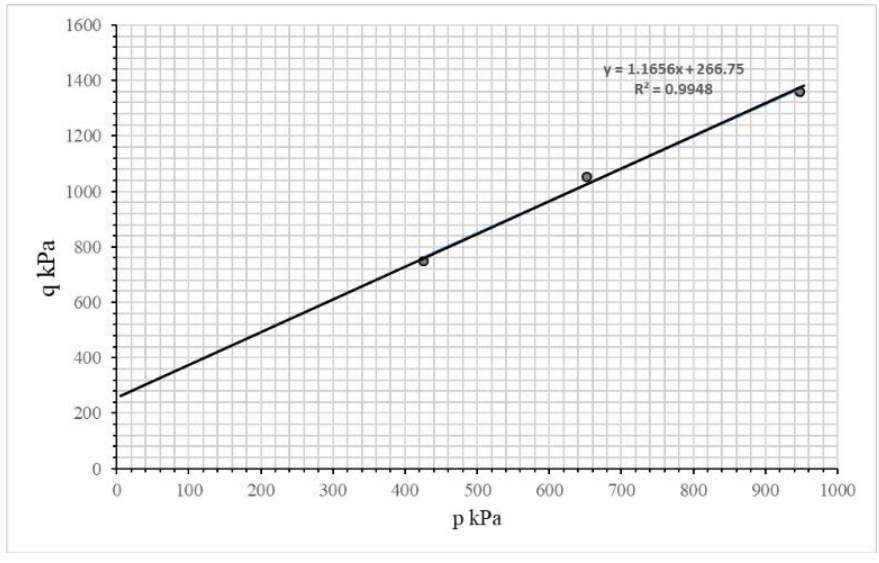

Figure 5. Shear stress $(q)$ - effective stress $(p)$ plotted to identify Drucker-Prager model parameters.

\subsubsection{Consolidation test}

An isotropic consolidation test was used to identify the plastic strain of the soil through applied loadingunloading cycles, and to calculate the volumetric elastic strain that can be subtracted from the volumetric total strain [22]. Three isotropic consolidation tests were conducted on the soil specimens extracted from the trench from three different points in the trench. In total, nine tests were conducted. The results of the sample extracted from the point located in the middle of the trench, where the applied load has the greatest effect, were selected to establish the soil parameters and curve of cap hardening. Figure 6 shows the results of the consolidation test.

The compression index $(C c)$ and swelling index $(C s)$ obtained from the isotropic consolidation test were used to calculate the $\lambda$ and $\kappa$ slopes of the normal consolidation and loading-unloading lines in the e-ln p plane using Equation (7) and Equation (8), respectively.

$$
\begin{aligned}
& \lambda=\frac{C c}{\ln 10} \\
& \kappa=\frac{C s}{\ln 10}
\end{aligned}
$$


These two parameters were used to establish the cap hardening curve that describes the evolution of the soil's plastic volumetric strain Figure 7, which is used as an input parameter of the Modified Drucker-Prager/Cap plasticity in the FE model to simulate the plastic behaviour of the filling soil. The plastic volumetric strain $\left(\varepsilon_{\mathrm{vp}}\right)$ was calculated using Equation 9.

$$
\varepsilon_{\mathrm{vp}}=\frac{\lambda-\kappa}{1+e_{0}} \ln \frac{p \prime}{p}
$$

where $p=$ effective stress, $p^{\prime}=$ mean effective stress, $e_{0}=$ void ratio, and $\lambda$ and $\kappa$ are the slopes of the normal consolidation and loading-unloading lines, respectively.

The soil parameter properties produced through the laboratory tests above are summarised in Table 1.

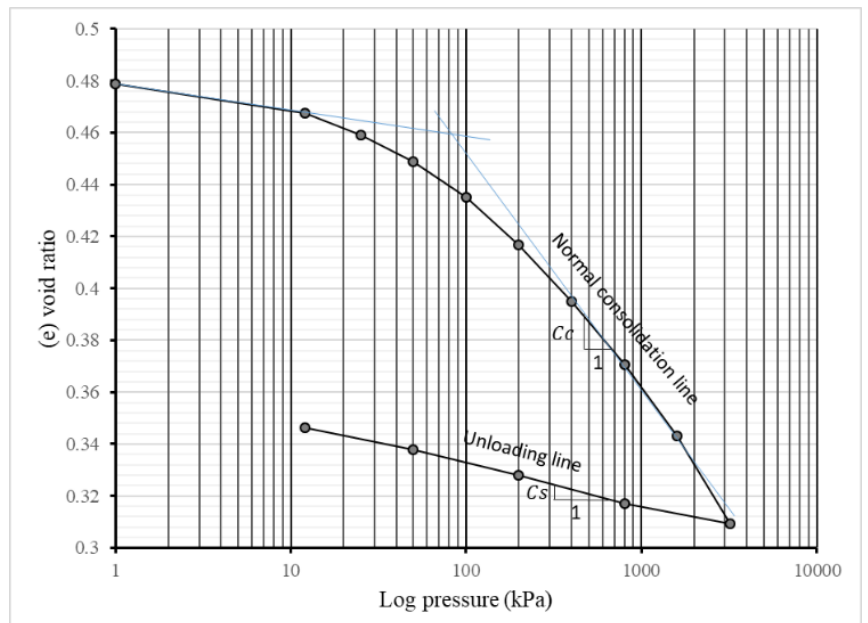

Figure 6. Results of the consolidation test used to identify soil properties.

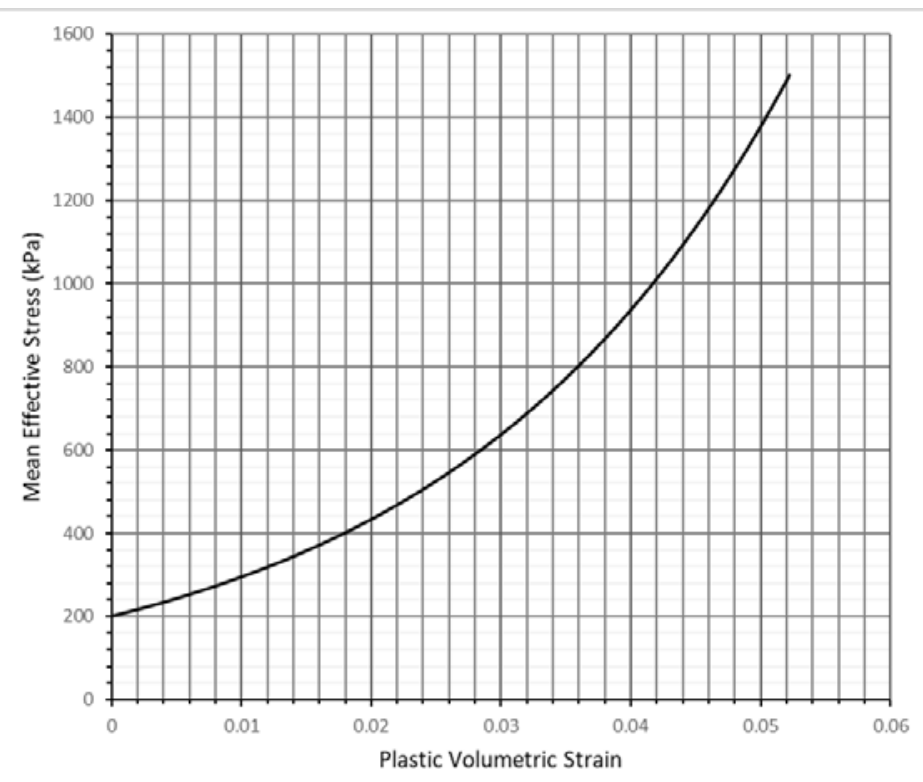

Figure 7. Evaluating the modified cap model hardening curve.

\section{The physical model}

There is a lack of field data concerning the configuration of one-over-one pipes installed in one trench; therefore, it was essential to build a physical model in the laboratory to test the new system of placing the pipes. The physical model had dimensions of $2.5 \times 0.5 \times 1 \mathrm{~m}^{3}$ and was embedded in the hydraulic rig. The laboratory test allows the identification of the mechanical properties and boundary condition parameters for the system under applied loading. The model included two PVC pipes $80 \mathrm{~mm}$ and $160 \mathrm{~mm}$ in diameter set in a wooden trench, embedded in a 
hydraulic steel rig. The two pipes were buried in the composite soil; the large pipe was placed at the top and the small pipe at the bottom. Strain gauges and linear vertical displacement transducers (LVDTs) were used to measure the pipe and soil deflection. A steel plate with dimensions $0.5 \times 0.25 \mathrm{~m}^{2}$ was used to simulate a truck tire footprint [23] using a compression load cell located between the hydraulic load arm and the tyre footprint to synchronise the applied load with the measured displacement. Figure 8 shows the setup of the physical model. All the measurement instruments were connected to a P3 strain indicator and recorder to continuously record the pipe and steel plate deflections from the LVDTs when the live load was applied.

Table 1. Parameters of the modified Drucker-Prager cap and Mohr-Coulomb constitutive model for the soil and bedding layer.

\begin{tabular}{|c|c|c|}
\hline Items & Parameters & Value \\
\hline \multirow{13}{*}{ Soil } & Density & $1685 \mathrm{~kg} / \mathrm{m}^{3}$ \\
\hline & $E^{\prime}$ & $16.943 \mathrm{MPa}$ \\
\hline & v & 0.295 \\
\hline & \multicolumn{2}{|c|}{ Drucker-Prager } \\
\hline & $\beta$ & 55 \\
\hline & K & 0.8 \\
\hline & $\psi$ & 15 \\
\hline & $\lambda$ & 0.044 \\
\hline & $\kappa$ & 0.0056 \\
\hline & $\mathrm{e}_{\mathrm{o}}$ & 0.48 \\
\hline & \multicolumn{2}{|c|}{ Mohr-Coulomb } \\
\hline & $\phi$ & 31.7 \\
\hline & $\mathrm{C}$ & 50 \\
\hline \multirow{5}{*}{ Bedding } & $1855 \mathrm{~kg} / \mathrm{m}^{3}$ & $1855 \mathrm{~kg} / \mathrm{m}^{3}$ \\
\hline & $\mathrm{E}$ & $100 \mathrm{MPa}$ \\
\hline & $\phi$ & 35 \\
\hline & $\mathrm{C}$ & 0 \\
\hline & 0 & 0.4 \\
\hline
\end{tabular}

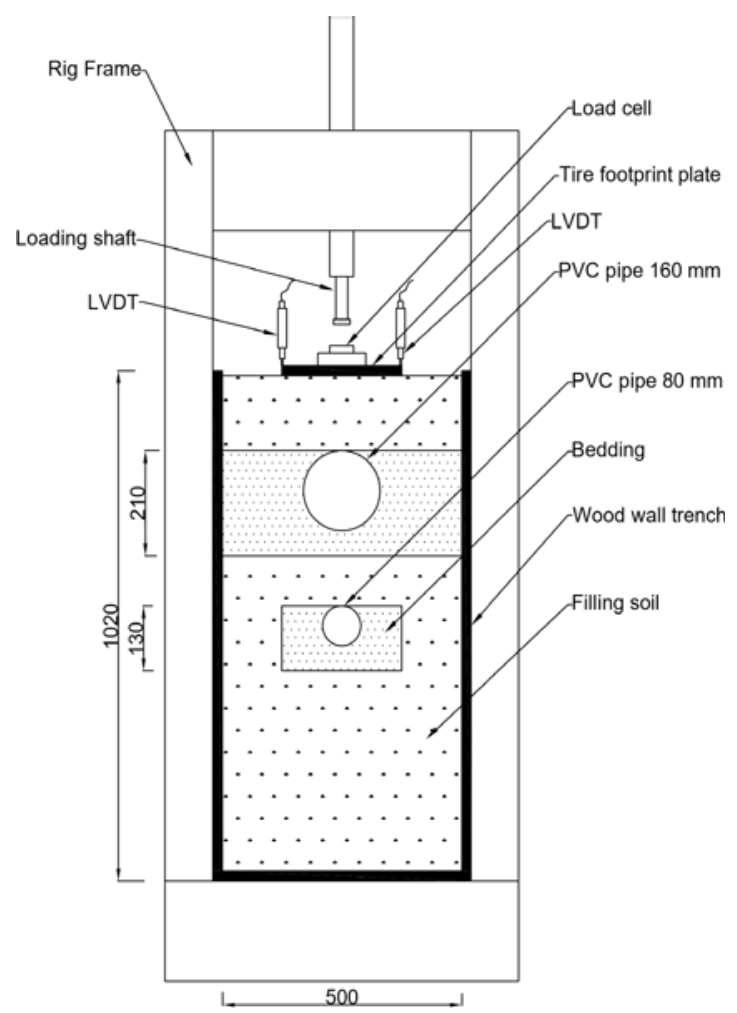

Figure 8. Setup of the trench in the hydraulic rig to test the performance of the system of the buried pipes in the soil. 


\section{FE model}

Two 3D FE models were created to simulate the new design. The first was built to simulate the physical laboratory model and was then used to validate the model parameters and boundary conditions. The first validated model was upgraded to a full-scale model of a separate sewer system using two PVC pipes, $500 \mathrm{~mm}$ and $1000 \mathrm{~mm}$ in diameter. The second model was used to investigate the rut of the tier footprint in two cases, when two PVC pipes were set in one trench relative to the conventional system when one pipe was laid in the trench under an H20 traffic load.

\subsection{FE model of physical model}

FE models were created to simulate the physical laboratory model, including the plate of the tire footprint, the load cell, pipes, bedding layers and filling soil. The models have the same dimensions and boundary conditions as the physical model. The mesh of the model includes 177,062 linear hexahedral elements of type C3D8R for the case of one pipe, and 210,782 elements for the case of two pipes laid in one trench. The boundary conditions and dimensions applied in the physical model were determined for the FE model. The material properties extracted from laboratory tests of each object were identified for the FE model using a modified Drucker-Prager cap constitutive model for both the physical FE model and the real-scale FE model to simulate the soil behaviour. The same series of loads applied in the physical model was used in the FE model to explore the behaviours of the soil and compare the physical and FE model results for validation. Figure 9 illustrates the results produced by the FE model and physical model with one pipe in one trench and Figure 10 shows the results for two pipes in the trench.

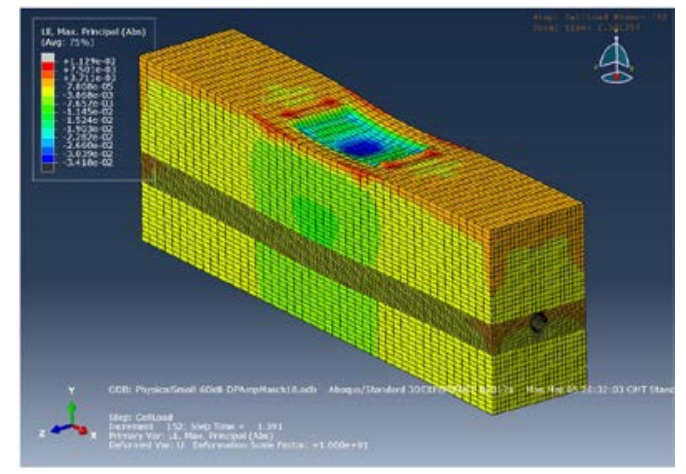

a

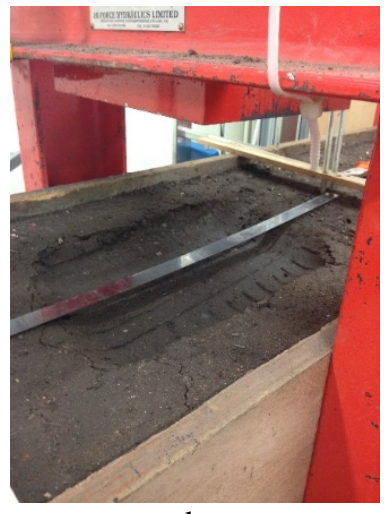

b

Figure 9. Visualisation results for (a) the FE model and (b) physical model with one pipe set in one trench under an H20 live load.

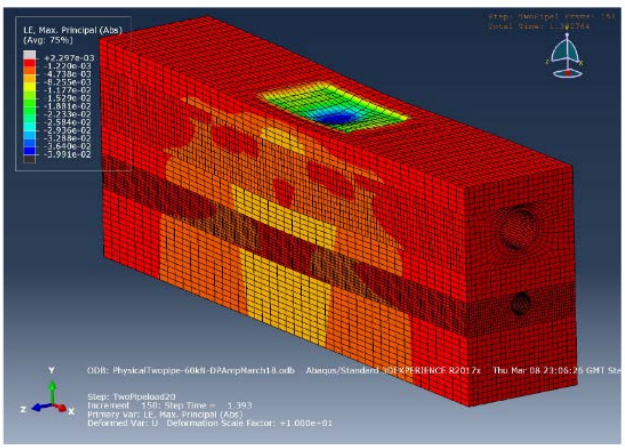

a

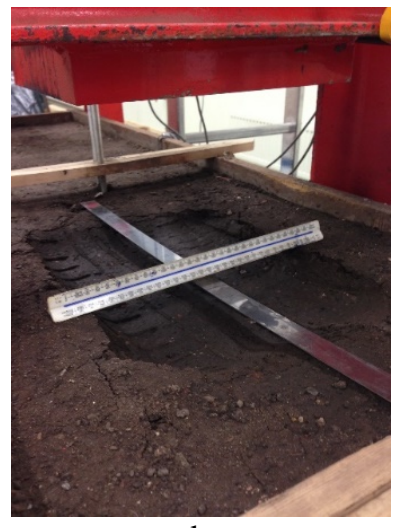

$\mathrm{b}$

Figure 10. Visualisation results for (a) the FE model and (b) physical model with two pipes set in one trench under an H20 live load.

The results of the comparison show acceptable consistency between the experimental results from the physical model and the FE model. The soil rut print at the centre of the physical model was $3.5 \mathrm{~cm}$ for the case of one pipe in the trench and $3.74 \mathrm{~cm}$ for two pipes in the trench. The FE model shows $3.4 \mathrm{~cm}$ for the case when one pipe was laid in the trench and $3.9 \mathrm{~cm}$ for the case of one pipe over another pipe in one trench. The results from both models demonstrate the mitigation of strain in the sanitary pipe when it is positioned below the storm pipe. 


\subsection{Full-scale FE model}

The 3D FE validated model at the laboratory scale was developed into a full-scale model. Conventional sewer systems typically use a minimum cover depth of $2 \mathrm{~m}$ to provide protection for a sewer system network with diameters of $1000 \mathrm{~mm}$ and above [24, 25]. These sewer system criteria were selected to test the structural integrity of the new installation method for a separate sewer system. The 3D FE model was applied with the real-scale dimensions including two PVC pipes buried at a soil cover depth of $2 \mathrm{~m}$ : a $500 \mathrm{~mm}$ sanitary pipe and a $1000 \mathrm{~mm}$ storm pipe. The same soil and bedding material properties used in the laboratory for the physical model were also used for the 3D FE real-scale model. The width and height of the whole model were selected to measure the extent to which a live load can affect the native soil around the trench occupied by the pipes [26]. The dimensions of the model were $10 \times 6 \times 10 \mathrm{~m}^{3}$ for the full-scale model. Two lanes representing two wheels of an H20 truck passing over the buried pipe section were positioned on the surface to apply the live load. Figure 11 illustrates the model of the set of pipes (500-1000 mm) with the storm pipe lying above the sanitary pipe in the same trench. Two types of ground surfaces were tested. The first used only soil cover which corresponded to the critical case during the installation process, while the second also used normal road surface layers, i.e., subgrade and pavement. The properties of the pavement used for the FE model were as follows: density $=2315 \mathrm{~kg} / \mathrm{m}^{3}$; modulus of elasticity = $1400 \mathrm{MPa}$. The ABAQUS 2017 package was used to implement the 3D FE model on the Liverpool John Moores University cluster, as the dimensions of the model required powerful high-performance computing. The model included 397,764 linear hexahedral elements of type C3D8R.

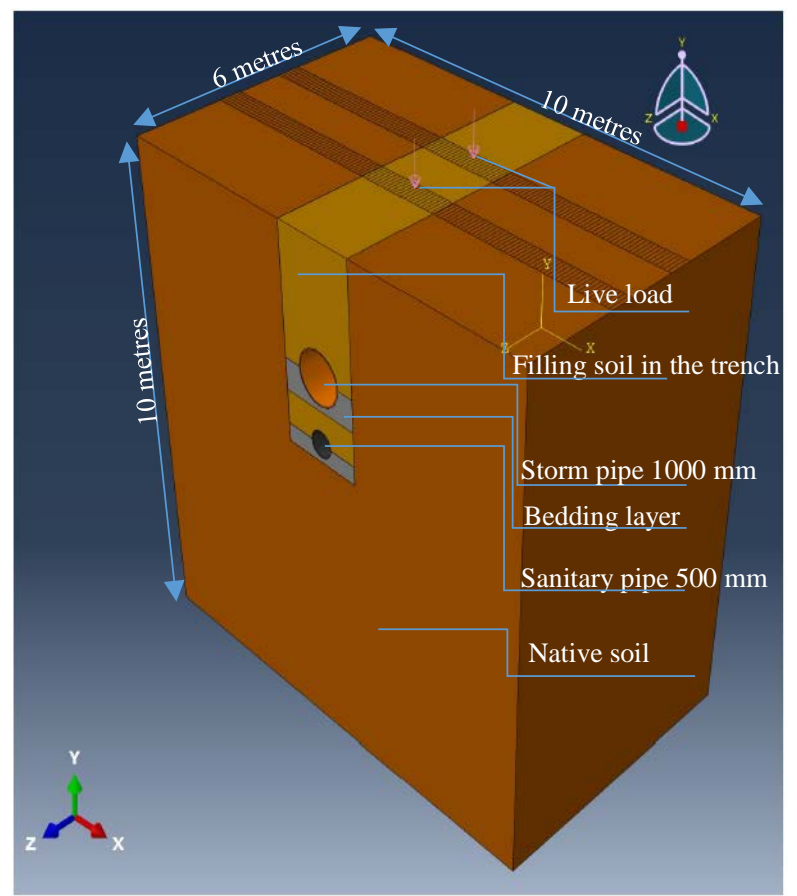

Figure 11. The model of a $1000 \mathrm{~mm}$ diameter storm pipe and $500 \mathrm{~mm}$ diameter sanitary pipe in a single trench.

The 3D FE full-scale model was used to explore the surface soil deflection when using the proposed system; the two sets of pipes in one trench model was compared with the traditional method. A traffic live load of H20 was selected for application to the real-scale model. Figure 12 shows a sample of the section visualisation of the 500-1000 mm diameter model with two pipes set in one trench.

The comparisons between the results of surface deformation along the length of pipe (6 metres) under effects of only applied traffic load (H20), when using a pavement at the surface and when using only the soil, in both cases - when using one pipe in the trench and when using two pipes - are presented in Figure 13. a, b, c and d. For the case where one pipe was placed in the trench, the deformation was reduced to $10.8 \mathrm{~mm}$ when the pavement was present and $13 \mathrm{~mm}$ when it was not (soil only). For the case where two pipes were placed in the trench, deformation of the surface was reduced to $9.6 \mathrm{~mm}$ when the pavement was present and $11.5 \mathrm{~mm}$ when it was not (soil only). The results show clearly that the filling soil deformation in the trench underneath the surface is the main factor causing this deflection and the pavement layer did not have a significant influence on the value of the filling soil deflection. 


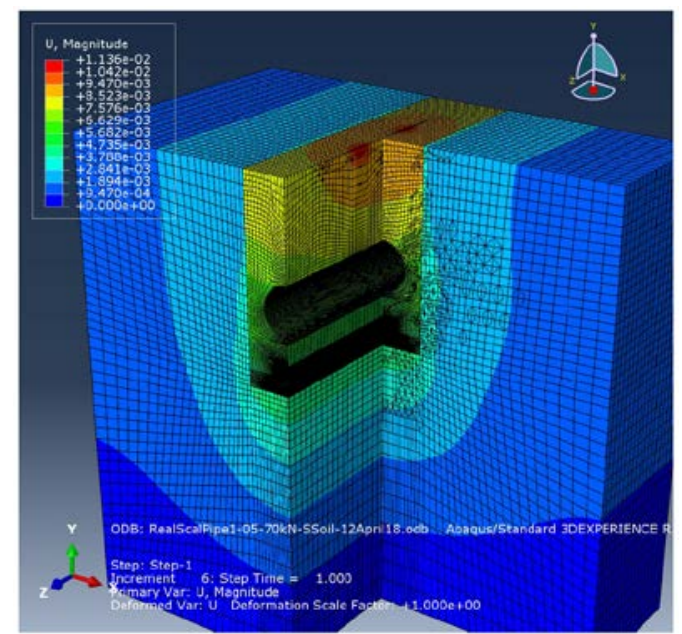

Figure 12. Section of visualisation results for the FE real-scale model when two pipes were laid in one trench under an applied H20 live load.

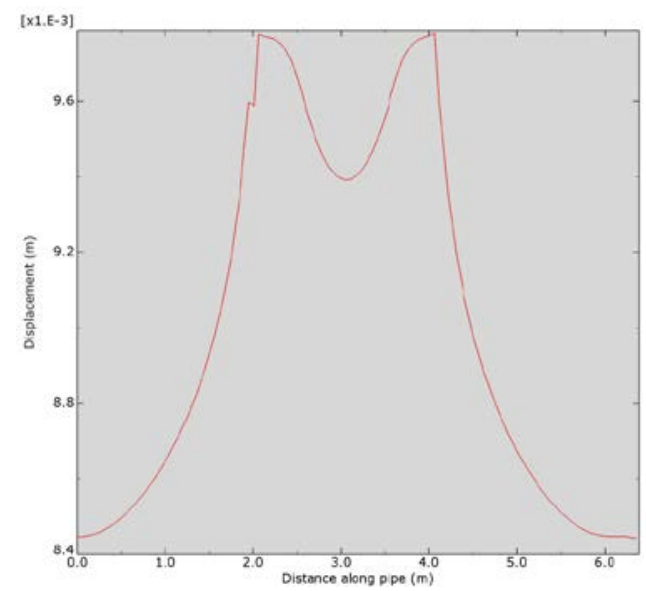

a

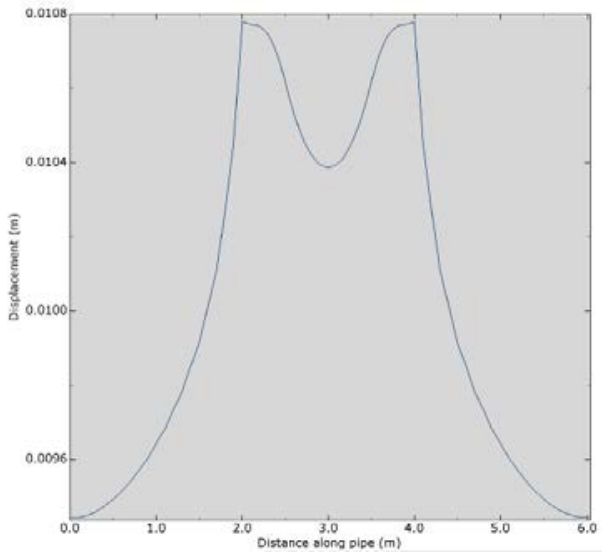

C

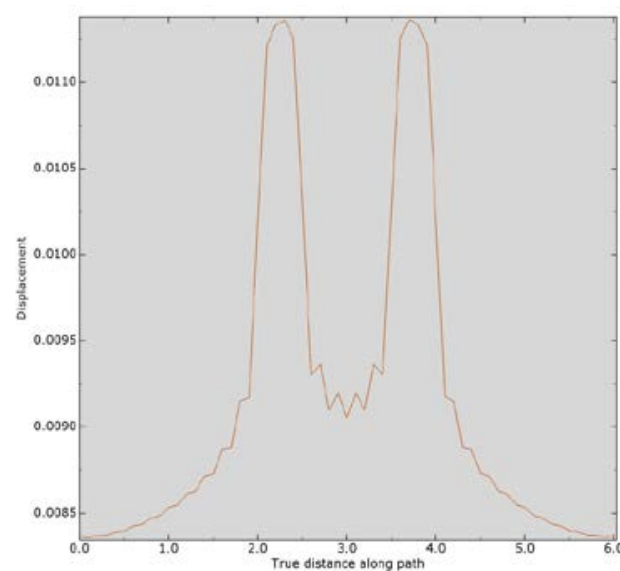

b

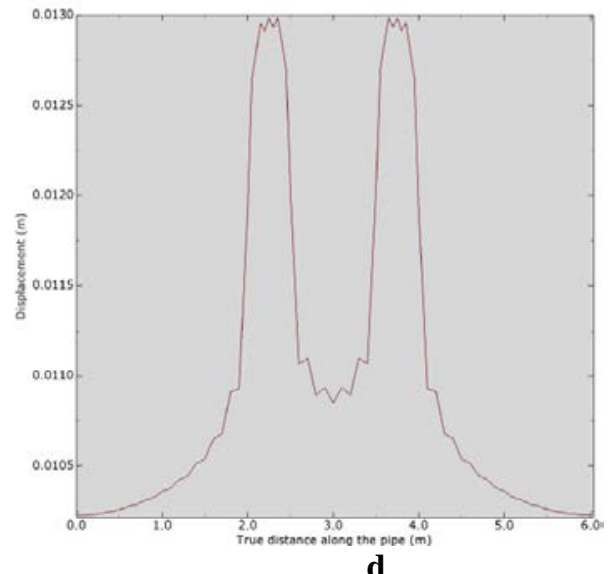

Figure 13. The comparison of the surface deformation under applied load when (a) using asphalt and two pipes set in the trench, (b) using soil and two pipes set in the trench, (c) using asphalt and one pipe set in the trench and (d) using soil and one pipe set in the trench.

Deformation of the surface soil occurred for the three configurations: when the $500 \mathrm{~mm}$ pipe was set in the trench, with the $1000 \mathrm{~mm}$ pipe in the trench and when both pipes were set in the trench. The surface soil deflection for accumulation of the deformation due to the weight of the soil column and applied load is illustrated in Figure 14. The results show there was more soil surface deformation when only the sanitary pipe (500 mm) was in the trench than when only the storm pipe $(1000 \mathrm{~mm})$ was in the trench. There was also less surface soil deformation 
when both pipes were set in the trench, as a result of an increase in the soil stiffness because two bedding layers were used, one for each pipe. The soil surface deflection was larger in the case of the one $500 \mathrm{~mm}$ pipe in the trench compared with the one $1000 \mathrm{~mm}$ pipe in the trench because the first pipe was deeper and required a large depth, thereby increasing the soil column weight [7].

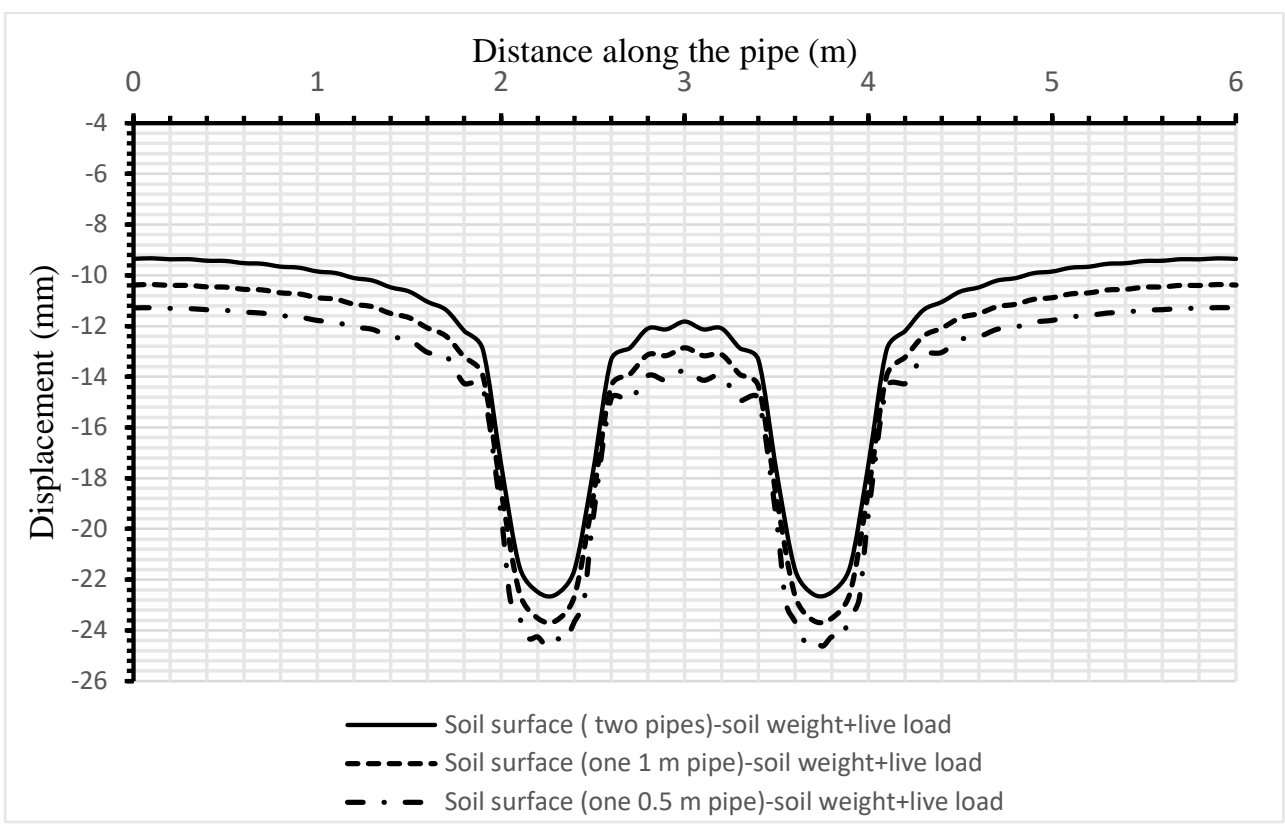

Figure 14. Comparison between the deflections of the soil surface under three cases for two pipes and when either one sanitary pipe or one storm pipe is in the trench.

\section{Conclusions}

The surface soil deformation was explored for two methods of installation of a separate sewer system: the traditional method when one pipe is set in the trench and a novel method when two pipes are set in a single trench, one over the other. The FE models were validated by using experimental results to investigate the influence of the methods of installing the pipes of the separate sewer system on the surface soil performance. The results show a slight decrease in surface soil deflection, approximately $3 \%$ to $10 \%$ when using two pipes in one trench compared with laying one pipe in the trench. This finding was explained in terms of the slightly increased soil stiffness, as two bedding layers were used in the trench with each pipe. The comparison between ruts in soil and pavement demonstrated that pavement does not make a big difference to using just soil and slightly decreased the stress on the filling soil underneath.

\section{References}

[1] Tsai CC, Meymand P, Dawson E, Wong SA. Behaviour of segmental pipeline protective vaults subjected to fault offset. Structure and Infrastructure Engineering. 2015;11(10):1369-1382.

[2] Rani S, Prasad N. Krishna S. Applicablity of Mohr Coulomb and Drucker Prager Models for assessment of undrained shear behaviour of clayey soils. International Journal of Civil Engineering and Technology (IJCIET). 2014; 5(10): 19.

[3] Law TM, Moore ID. Numerical modeling of tight fitting flexible liner in damaged sewer under earth loads. Tunnelling and underground space technology. 2007;22(5-6):655-665.

[4] Xu M, Shen D, Rakitin B. The longitudinal response of buried large-diameter reinforced concrete pipeline with gasketed bell-and-spigot joints subjected to traffic loading. Tunnelling and Underground Space Technology. 2017;64:117-132.

[5] Abolmaali A, Kararam A. Nonlinear finite-element modeling analysis of soil-pipe interaction. International Journal of Geomechanics. 2011;13(3):197-204.

[6] Kunert HG, Otegui JL, Marquez A. Nonlinear FEM strategies for modeling pipe-soil interaction. Engineering Failure Analysis. 2012;24:46-56. 
[7] Zhou M, Du YJ, Wang F, Arulrajah A, Horpibulsuk S. Earth pressures on the trenched HDPE pipes in finegrained soils during construction phase: Full-scale field trial and finite element modeling. Transportation Geotechnics. 2017;12:56-69.

[8] Kouretzis GP, Sheng D, Sloan SW. Sand-pipeline-trench lateral interaction effects for shallow buried pipelines. Computers and Geotechnics. 2013;54:53-59.

[9] Jung JK, Koo DH, Zhang K. Verification of the pipe depth dependent model using a finite element analysis. Tunnelling and Underground Space Technology. 2014;39:34-40.

[10] Akinay E, Kilic H. Use of emperical approaches and numerical analyses in design of buried flexible pipes. Scientific Research and Essays. 2010;5(24):3972-3986.

[11] Tian Y, Liu H, Jiang X, Yu R. Analysis of stress and deformation of a positive buried pipe using the improved Spangler model. Soils and Foundations. 2015;55(3):485-492.

[12] Kang J, Jung Y, Ahn Y. Cover requirements of thermoplastic pipes used under highways. Composites Part B: Engineering. 2013;55:184-192.

[13] Sargand SM, Masada T, Tarawneh B, Gruver D. Field performance and analysis of large-diameter highdensity polyethylene pipe under deep soil fill. Journal of Geotechnical and Geoenvironmental Engineering. 2005;131(1):39-51.

[14] McGrath TJ, Moore ID, Hsuan YG. Updated test and design methods for thermoplastic drainage pipe. Washington, D.C.: Transportation Research Board; 2009.

[15] Chai JC, Miura N. Traffic-load-induced permanent deformation of road on soft subsoil. Journal of Geotechnical and Geoenvironmental Engineering. 2002;128(11):907-16.

[16] Kim, Y.-R., H. Ban, and S. Im, Impact of Truck Loading on Design and Analysis of Asphaltic Pavement Structures. 2010, Mid-America Transportation Center: USA. p. 23.

[17] DEFRA. National build standards design and construction of new gravity foul sewers and lateral drains, in Water Industry Act 1991 Section 106B, Flood and Water Management Act 2010 Section 42. Department for Environment Food and Rural Affairs, UK. 2011;p. 36.

[18] Moser AP, Folkman S. Buried pipe design, 3rd ed. McGraw-Hill; 2008.

[19] Gross D, Seelig T. Fracture mechanics with an introduction to micromechanics. mechanical engineering. Ling FF ed. New York: Springer-Verlag Berlin Heidelberg; 2011.

[20] Ti KS, Huat BB, Noorzaei J, Jaafar MS, Sew GS. A review of basic soil constitutive models for geotechnical application. Electronic Journal of Geotechnical Engineering. 2009;14:1-8.

[21] ABAQUS. Abaqus 6.12, Analysis User’s Manual. Systèmes D, Editor. USA: Dassault Systèmes; 2012.

[22] Helwany S. Applied soil mechanics with ABAQUS applications. Hoboken, NJ, USA: John Wiley \& Sons, Inc.; 2007.

[23] Kang JS, Stuart SJ, Davidson JS. Analytical evaluation of maximum cover limits for thermoplastic pipes used in highway construction. Structure and Infrastructure Engineering. 2013;9(7):667-674.

[24] Bizier P, editor. Gravity sanitary sewer design and construction. Water Environment Foundation (WEF); 2007.

[25] Read GF, editor. Sewers: replacement and new construction. Elsevier; 2004.

[26] Najafi M, Sever VF. Structural capabilities of no-dig manhole rehabilitation. Water Environment Research Foundation. 2015; p.223.

(C) 2019 by the author(s). This work is licensed under a Creative Commons Attribution 4.0 International License (http://creativecommons.org/licenses/by/4.0/). Authors retain copyright of their work, with first publication rights granted to Tech Reviews Ltd. 